\title{
Review of the Development of Dyes for Dye-Sensitized Solar Cells
}

\author{
Received November 4, 2019; accepted November 15, 2019
}

\author{
Sang-Hun Namª, ${ }^{\mathrm{a}, \mathrm{b}}$ Kyu Hwan Lee ${ }^{\mathrm{a}}$, Jung-Hoon $\mathrm{Yu}^{\mathrm{a}}$, and Jin-Hyo Boo ${ }^{\mathrm{a}, \mathrm{b}, *}$ \\ aDepartment of Chemistry, Sungkyunkwan University, Suwon 16419, Republic of Korea \\ ${ }^{b}$ Institute of Basic Science, Sungkyunkwan University, Suwon 16419, Republic of Korea \\ *Corresponding author E-mail: jhboo@skku.edu
}

\begin{abstract}
Dye-sensitized solar cells (DSSCs) have attracted considerable attention over the last 25 years owing to their potential for the low-cost conversion of photovoltaic energy. The most important DSSC component is the sensitizer dye, which is largely responsible for light harvesting and charge separation. Although tremendous research efforts have been focused on dye development, many challenges remain and a deeper understanding of the design rules for DSSC sensitizers is required to obtain efficient and long-term stable DSSCs. State-of-the-art DSSCs based on single sensitizers have reached power conversion efficiencies (PCEs) of $>11.5 \%$ for ruthenium dyes, $>13 \%$ for porphyrin dyes, and $>14 \%$ for metal-free organic dyes. However, the highest efficiency officially recognized by the National Renewable Energy Laboratory is only $11.9 \%$, achieved by the Sharp Co., Japan, in 2013. Furthermore, there has been a lack of significant milestones in active commercialization, particularly with respect to exploiting the near-infrared region for higher PCEs and greater device durability. While ruthenium-based dyes have some disadvantages for practical application in DSSCs, both porphyrin and metal-free organic dyes have attracted considerable interest. In this review, we summarize recent progress in the rational design of ruthenium dyes, porphyrin dyes, metal-free organic dyes, and natural dyes for use in DSSCs.
\end{abstract}

Keywords: Dyes, Sensitizers, Dye-sensitized solar cells, Photo-to-current conversion efficiency

\section{Introduction}

Currently, most energy consumed globally originates from fossil fuels. However, it is apparent that fossil fuel resources will be exhausted within centuries, and environmental problems related to fossil fuel use, such as air pollution and the greenhouse effect, cannot be overlooked. Accordingly, in recent years, research efforts have been focused toward developing eco-friendly renewable energy, including solar, geothermal, wind, tidal, and hydro energy. In particular, solar cells, which convert solar energy into electricity, are emerging as the most realistic and universal option for replacing traditional energy sources. Currently, most commercial solar cells are silicon solar cells, in which the photon conversion process relies on a semiconductor $\mathrm{p}-\mathrm{n}$ junction. Although silicon solar cells have high photoelectric efficiencies, their manufacturing processes are complicated and expensive. In contrast, dye-sensitized solar cells (DSSCs) are economically feasible, with manufacturing costs that are only one-fifth of that of conventional silicon solar cells, and can be manufactured in an eco-friendly manner, which is advantageous for commercialization and various applications [1-6].

DSSCs were first developed in 1991 by the Grätzel group at the Swiss Federal Institute of Technology $[7,8]$. However, some technical challenges remain, with the greatest issue being that the efficiencies of DSSCs are inferior to those of existing silicon solar cells. Figure 1 shows the efficiencies of various solar cell devices developed until recently. The highest efficiency for a DSSC officially recognized by the
National Renewable Energy Laboratory has remained $11.9 \%$ since 2013 [9]. As silicon solar cells can achieve efficiencies of $25 \%$, the most urgent priority for DSSCs is improving the efficiency [10-12].

DSSCs consist of a photoelectrode, a counter electrode, and an electrolyte. The photoelectrode is coated with a metal oxide semiconductor thin film on which a dye is adsorbed on a transparent electrode material. Essentially, dye molecules, which act as sensitizers, are chemisorbed as a monomolecular layer on the surface of the semiconductor film [11]. Dyes are usually classified as metal-complexbased dyes or metal-free organic dyes. Generally, metal-complexbased dyes are composed of a central metal ion and a secondary ligand such as polypyridine. Among metal complexes, $\mathrm{Ru}$ complexes are known to have excellent photoelectric conversion efficiencies. Representative Ru complexes include N3, N719, and N749 (commonly known as black dye) $[12,13]$. Metal-free organic dyes, which have high molar extinction coefficients in the visible and near-infrared regions, have been studied in recent years owing to their simplicity, low synthesis costs, and environmental friendliness [11].

The purpose of this review is to discuss recent progress and the rational design criteria used in the structural design of $\mathrm{Ru}$ dyes, porphyrin dyes, metal-free organic dyes, and natural dyes for use in DSSCs. An overview of the principles of various dyes, as well as the efficiencies of the corresponding DSSCs, are provided. 


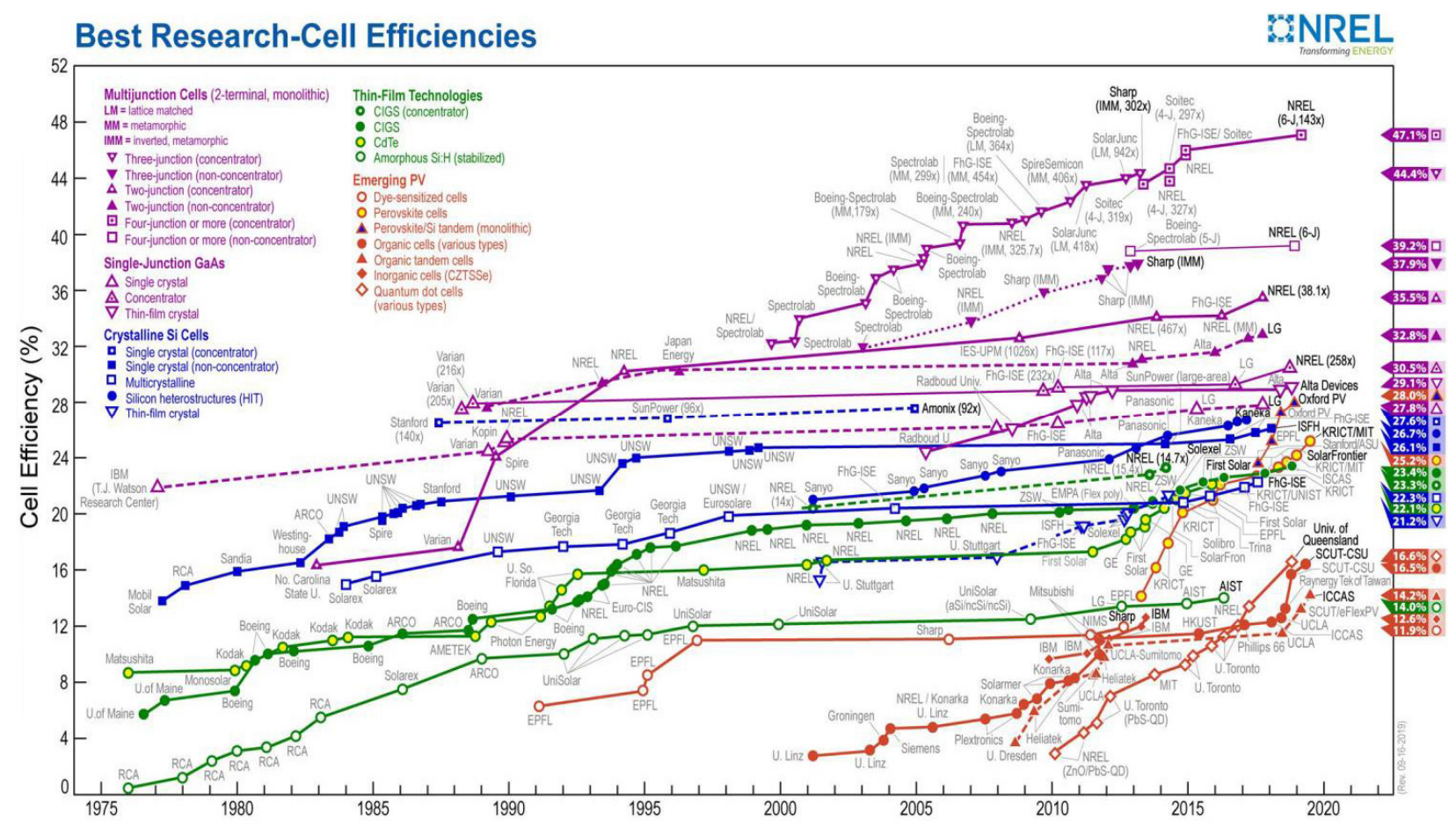

Figure 1. (Color online) Efficiencies of various solar cells $[9,10]$.

\section{Theoretical background}

The performance of a photovoltaic device is generally characterized by means of the photocurrent-voltage curve ( $J-V$ curve) and the incident photo-to-current conversion efficiency (IPCE). The photoconversion efficiency (PCE; $\eta$ ) of a DSSC is defined as the ratio of the maximum photoelectric output energy $\left(P_{\max }\right)$ to the incident solar energy $\left(P_{\text {in }}\right)$, as shown in Eq. (1).

$$
\eta=P_{\text {max }} / P_{\text {in }}=J_{\text {max }} \times V_{\text {max }} / P_{\text {in }}
$$

where $P_{\text {in }}$ is the incident light power (generally $100 \mathrm{~mW} \mathrm{~cm}^{-2}$ ) on the device surface per unit area under standard conditions, and $P_{\max }$ can be expressed as the product of the maximum current $\left(J_{\max }\right)$ and the maximum voltage $\left(V_{\max }\right)$.

Figure 2 shows a typical $J-V$ curve with respect to the performance of a DSSC. Here, the short-circuit current $\left(J_{\text {sc }}\right)$ refers to the current flowing when the voltage across the solar cell is $0 \mathrm{~V}$ (shorted). In an ideal solar cell, this value and the actual generated current are the same, so $J_{\mathrm{sc}}$ is the maximum current that can be drawn from the solar cell. In addition, the open-circuit voltage $\left(V_{\mathrm{oc}}\right)$, which is the voltage difference across the solar cell when the current is $0 \mathrm{~A}$, corresponds to the maximum voltage that can be obtained from the solar cell. The fill factor ( $f f$ ), also called the curve factor, represents the quality of a solar cell and is defined as the ratio of the output to the product of $J_{\mathrm{sc}}$ and $V_{\text {oc. }}$ In other words, this parameter can be interpreted as the ratio of two rectangular areas, as shown in Eq. (2), with the ff indicating the degree to which $J_{\mathrm{mp}}$ and $V_{\mathrm{mp}}$ are similar to $J_{\mathrm{sc}}$ and $V_{\mathrm{oc}}$.

$$
f f=\frac{\left(J_{m p} \times V_{m p}\right)}{\left(J_{s c} \times V_{o c}\right)}
$$

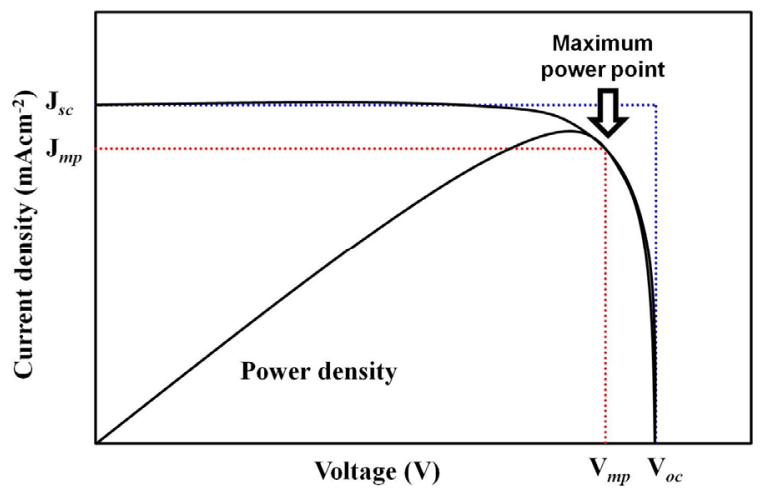

Figure 2. (Color online) Typical photocurrent-voltage ( $J-V$ for a DSSC.

The overall PCE $(\eta), V_{\mathrm{oc}}, J_{\mathrm{sc}}$, and $f f$ of a DSSC are determined from the $J-V$ curve. Therefore, their relationship can be expressed by Eq. (3) [14]:

$$
\eta=P_{\max } / P_{\text {in }}=J_{\text {sc }} \times V_{\text {oc }} \times f f / P_{\text {in }}
$$

$J_{\mathrm{sc}}\left(\mathrm{mA} \mathrm{cm}^{-2}\right)$, which corresponds to the photocurrent per unit area produced in the external circuit under irradiation, is strongly affected by the following characteristics: (i) the light-harvesting capability of the dye sensitizer (molar extinction coefficient and absorption spectral range); (ii) energy-level alignment; and (iii) the molecular orientation and arrangement of the sensitizers on the semiconductor surface [15-17]. The IPCE spectrum, defined as the photocurrent density produced in the external circuit under monochromatic illumination divided by the incident photon flux, is widely used and useful for sensitizer evaluation in DSSCs. 


\section{Results and discussion}

\section{1) Structure and operating principle of DSSCs}

The basic structure of a DSSC is shown in Fig. 3 [18]. Typically, a DSSC is composed of a photoelectrode, a counter electrode, and an electrolyte. The photoelectrode consists of a transparent conductive oxide (TCO) glass substrate, a metal oxide semiconductor such as $\mathrm{TiO}_{2}$ nanoparticles, and a dye such as a $\mathrm{Ru}$ complex. A glass substrate is connected to both the anode and the cathode, and the $\mathrm{TiO}_{2}$ nanoparticle semiconductor film is coated on the cathode glass substrate. In general, fluorine-doped tin oxide (FTO) is used instead of indium tin oxide for TCO glass substrates in DSSCs because FTO is more thermally stable at temperatures higher than $500{ }^{\circ} \mathrm{C}$, which is advantageous for sintering at high temperatures, as required for the crystallization of mesoporous $\mathrm{TiO}_{2}$ [12]. Various metal oxide semiconductors are available for use in DSSCs, including $\mathrm{TiO}_{2}, \mathrm{ZnO}$, and $\mathrm{SnO}_{2}$ [19-21]. However, $\mathrm{TiO}_{2}$ is most commonly used to achieve alignment between the energy band structures of the metal oxide should and the dye. In particular, the semiconductor electrode material for DSSCs should have a relatively large band gap and an appropriate conduction

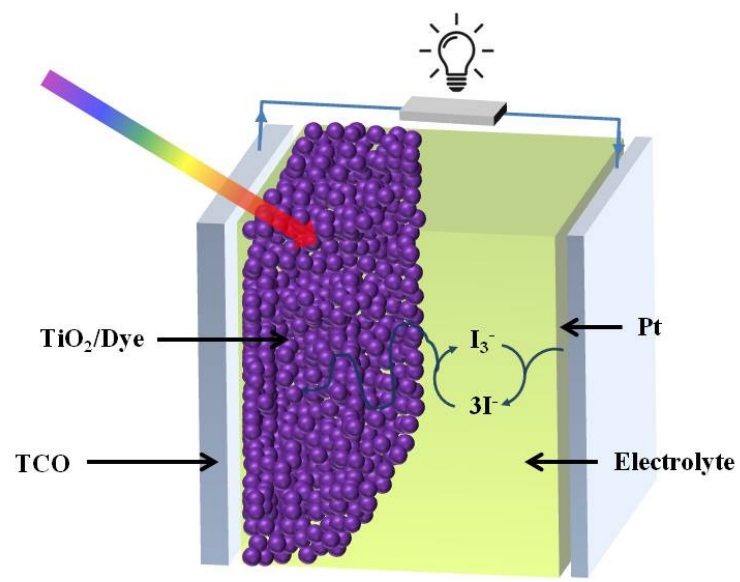

Figure 3. (Color online) Basic structure of a DSSC [18].

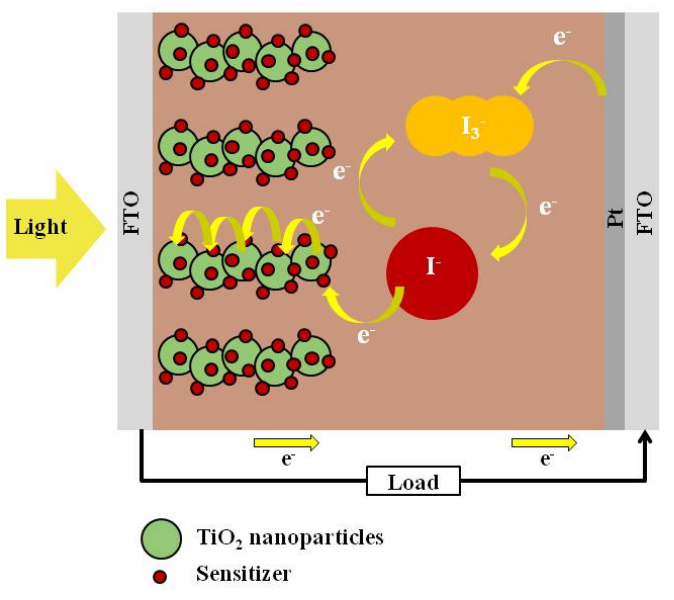

(a) band energy value because it is difficult to inject electrons from the dye if the conduction band energy is higher than the lowest unoccupied molecular orbital (LUMO) energy of the dye. For typical Ru-based dyes (N3, N719), the available metal oxides are extremely limited, and $\mathrm{TiO}_{2}$ is an ideal material because the conduction band energy is $\sim 0.2 \mathrm{eV}$ lower than the energy of the dye's LUMO [22,23].

The counter electrode, which is connected to the anode, usually consists of Pt coated on a TCO glass substrate. Pt is typically used because it exhibits high oxidation resistance while catalyzing the reduction-oxidation (redox) reaction of the electrolyte. However, as a precious metal, Pt is expensive and a limited resource. Recently, carbon black [24], carbon nanoparticles [25], carbon nanotubes [26,27], and graphene nanosheets $[15,28,29]$ have been used as alternative materials. Other electrode materials including conducting polymers and metals such as stainless steel are also being investigated [16].

The electrolyte must contain a redox material such as an iodide/ triodide redox couple [17,30-33], a bromide/tribromide redox couple [34], a sulfur-based system [35], or a metal-based redox couple [36] such as $\mathrm{Co}(\mathrm{II}) / \mathrm{Co}(\mathrm{III})$ complexes [37]. Most commonly, iodide/triodide redox couples are used.

Figure 4(a) shows a schematic diagram of the electron transfer path in a DSSC, whereas Fig. 4(b) shows a diagram describing the electron transfer process as an energy band structure. The main steps in the electron transfer process, as indicated on the energy band structure in Fig. 4(b), are as follows. When sunlight enters the cell, it is absorbed by the dye and the highest occupied molecular orbital (HOMO) electrons in the dye are excited to the LUMO (1). The excited electrons are then injected into the conduction band of $\mathrm{TiO}_{2}$ (2). Some electrons trapped in the mesoporous $\mathrm{TiO}_{2}$ nanoparticles may undergo recombination reactions, either being returned to the dye (4) or reducing triodide in the electrolyte (5). The electrons move to the transparent electrode through the interface between the nanoparticles (3), flow to the external circuit to transfer the electrical energy to the counter electrode (7). The dye is reduced by receiving electrons from the electrolyte solution, equivalent to the number of electrons transferred to $\mathrm{TiO}_{2}$ (6), and the iodide/triodide redox couple in the electrolyte receives electrons from the counter electrode through the redox process and transfers them to the dye (8) [11].

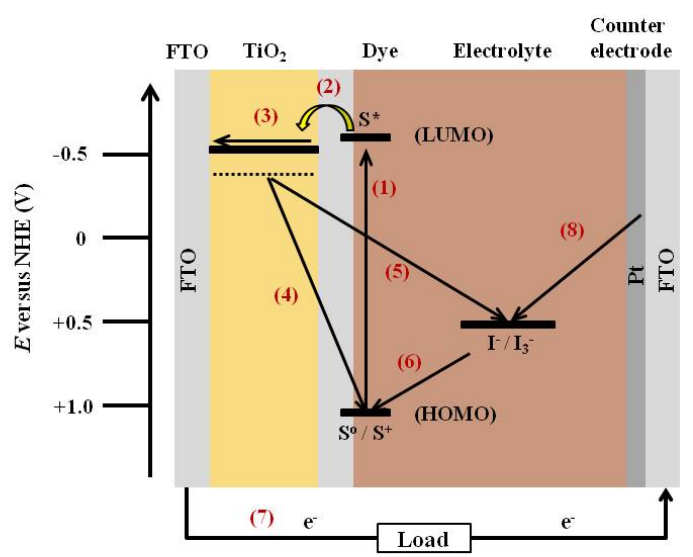

(b)

Figure 4. (Color online) (a) Schematic diagram of the DSSC electron transfer path and (b) DSSC electron transfer as an energy band structure [11]. 
2) Ideal dye properties for enhancing DSSC efficiency

Most dyes used in DSSCs are either metal-complex-based dyes or metal-free organic dyes, as described above. In general, the following properties should be considered when choosing a dye.

1. As most solar energy is concentrated in the visible and infrared regions, the dye must absorb light in not only the entire visible region but also the near-infrared region below $920 \mathrm{~nm}$.

2. To adsorb on the semiconductor film, the dye must interact strongly with metal oxides. To this end, reactive groups such as carboxylate or phosphate are typically introduced to form chemical bonds with metal oxides. When absorbing light, electrons excited to the LUMO of the dye should be injected into the conduction band of the metal oxide without loss.

3. The energy levels of the dye should be in alignment with the energy levels of the metal oxide and the electrolyte. To transfer electrons to the conduction band of $\mathrm{TiO}_{2}$, the LUMO of the dye must be higher than the conduction band of the metal oxide, and the HOMO of the dye must be lower than the HOMO of the electrolyte to receive a sufficient electron supply from the electrolyte.

4. The dye must have good heat and light stability with a redox turnover of at least 108 , which is equivalent to a period of approximately 20 years under natural light.

5. The excited state of the dye must have a long lifetime to achieve injection of all of the excited electrons into the conduction band of the metal oxide before the dye returns to its ground state $[11,38,39]$.

To meet these requirements, several dyes have been developed since the Ru-based N3 dyes first reported by the Grätzel group. In the following sections, the principles of various dyes are summarized and various dyes developed relatively recently are introduced.

\section{3) Metal-complex-based dyes}

\section{Ru dyes}

Most organometallic dyes studied to date have structures in which effective charge separation can occur between metals and ligands. Figure 5 shows the location of the HOMO and LUMO on the structure of T18, a Ru-based dye developed by Kisserwan et al., and Fig. 6 shows a visualization of the frontier molecular orbitals [40]. As shown, charge separation is effectively achieved between Ru metal and the polypyridine ligand and between the NCS ligand and Ru metal in

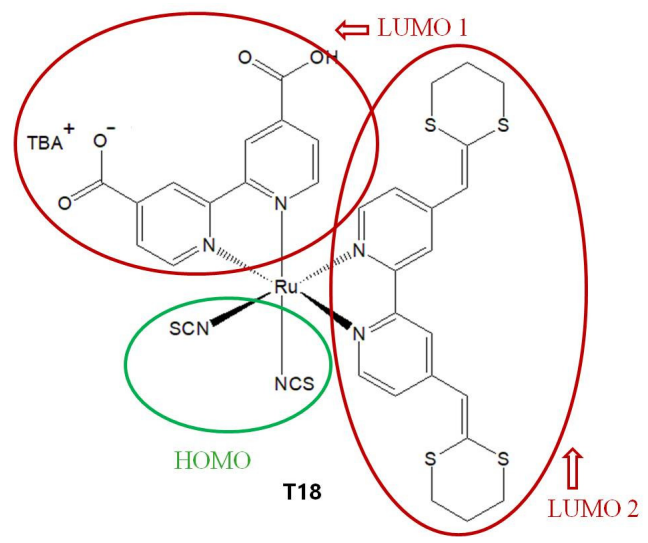

Figure 5. (Color online) HOMO and LUMO on the structure of T18 [13]. the visible region. When the dye absorbs light, electrons in the HOMO are excited to the LUMO and then the excited electrons are injected into the metal oxide.

The behavior of the ligand is very important in the chargeseparation structure. When sunlight enters the metal complex, the electrons in the $\mathrm{t} 2 \mathrm{~g}$ orbital of the metal absorb sunlight, which causes instantaneous spatial charge separation and electron transfer to the $\pi^{\star}$ level of the ligand. This process is called metal-to-ligand charge transfer (MLCT), and the efficiency of the dye depends on how efficiently this process occurs.

$\mathrm{Ru}$ complexes that exhibit charge separation are usually composed of a central Ru metal, bipyridine or tetrapyridine ligands, and an auxiliary NCS ligand. Figure 7 shows the structures of N3, N719, and N749 as representative Ru dyes. The N3 dye is a Ru(II) complex $\left(\mathrm{RuL}_{2} \mathrm{X}_{2}\right)$ consisting of two dipyridyl ligands, which donate two $\mathrm{N}$ electrons, and two X ligands (-NCS), which donate one $\mathrm{N}$ donor electron. Several other Ru-based dyes have been developed since the Grätzel group first reported the N3 dye in 1991. Ru-based dyes are known to have good photoelectric properties because they exhibit broad absorption and have an appropriate energy band structure $[11,40]$.

One method for achieving highly efficient dyes is to significantly increase the lifetime of the excited state and the absorbance in the visible range. Variation of the $\mathrm{X}$ ligand, which donates one electron, has been studied to produce a dye that meets these requirements (Table I) [41]. During the development of the N3 dye, -NCS was selected from among various electron-donor ligands (-NCS, $-\mathrm{CN},-\mathrm{Cl}$, $-\mathrm{Br},-\mathrm{I}$, and $\mathrm{H}_{2} \mathrm{O}$ ) owing to its MLCT ability. The absorption bands of the $\mathrm{RuL}_{2}(\mathrm{NCS})_{2}$ complex at 534 and $396 \mathrm{~nm}$ show that this ligand provides light absorption ability at longer wavelengths than the other ligands, indicating that charge transfer will be much easier. In addition, the redox potential of this complex is also high $(0.85 \mathrm{~V}$ vs SCE), which means that $\pi$-backbonding (between the $2 \mathrm{~g}$ orbital of the metal and the vacant ligand orbital) occurs during electron transition

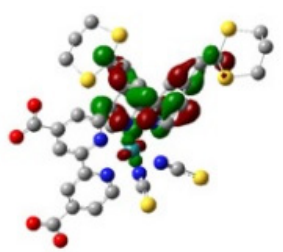

LUMO2

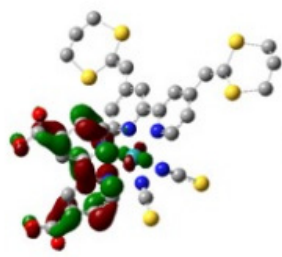

LUMO1

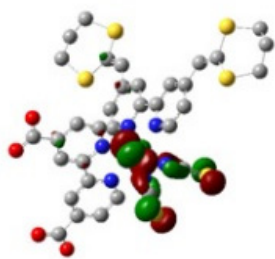

HOMO

Figure 6. (Color online) Frontier molecular orbital diagram of T18 [13]. 


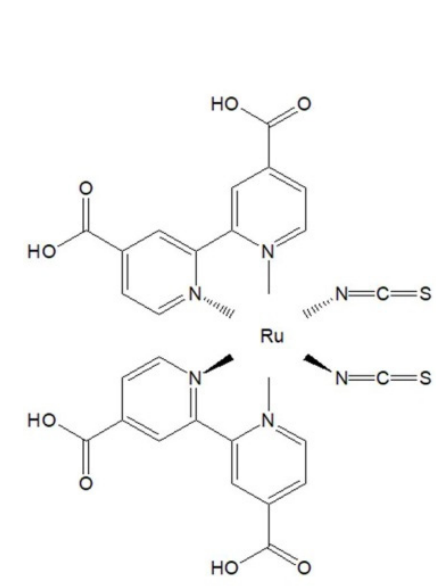

(a)

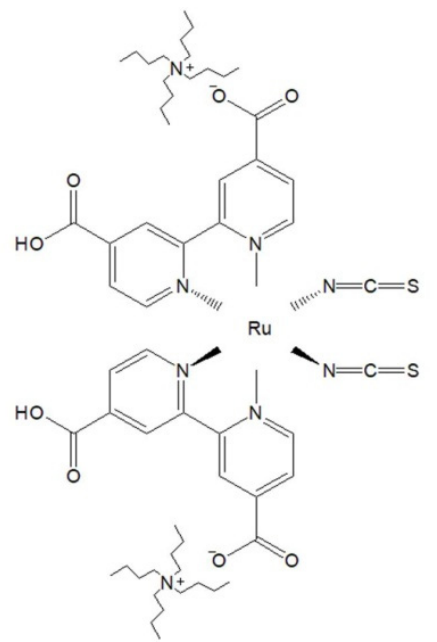

(b)

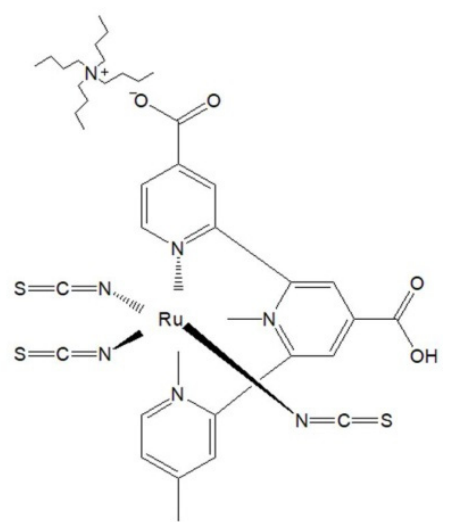

(c)

Figure 7. Representative Ru dyes: (a) N3, (b) N719, and (c) N749 (black dye).

Table I. Absorption, luminescence, and electrical properties of $\mathrm{RuL}_{2} \mathrm{X}_{2}$ complexes [41].

\begin{tabular}{|c|c|c|c|c|c|c|c|}
\hline \multirow{2}{*}{ Complex $^{a}$} & \multirow{2}{*}{$\begin{array}{l}\text { Absorption max }(\mathrm{nm})^{b} \\
{\left[E\left(10^{4} \mathrm{M}^{-1} \mathrm{~cm}^{-1}\right)\right]}\end{array}$} & \multicolumn{2}{|c|}{ Emission max (nm) } & \multicolumn{2}{|c|}{ Emission lifetime $^{d} \tau(\mathrm{ns})$} & \multirow{2}{*}{$\begin{array}{c}\Phi \text { at } 125 \mathrm{~K} \\
(\%)\end{array}$} & \multirow{2}{*}{$\begin{array}{l}E^{o e} \\
(\mathrm{eV})\end{array}$} \\
\hline & & $298 \mathrm{~K}$ & $125 \mathrm{~K}$ & $298 \mathrm{~K}$ & $125 \mathrm{~K}$ & & \\
\hline $\mathrm{RuL}_{2}(\mathrm{NCS})_{2}$ & $534[1.42], 396[1.40], 313[3.12]$ & $755^{b}$ & 718 & 50 & 960 & 0.40 & $0.85^{f}$ \\
\hline $\mathrm{RuL}_{2}(\mathrm{CN})_{2}$ & $493[1.45], 365[1.20], 310[3.90]$ & 702 & 700 & 166 & 1123 & 1.5 & 1.16 \\
\hline $\mathrm{RuL}_{2} \mathrm{Cl}_{2}$ & $534[0.96], 385[1.01], 309[4.13]$ & $\sim 800^{c}$ & 800 & & 105 & 0.074 & 0.57 \\
\hline $\mathrm{RuL}_{2} \mathrm{Br}_{2}$ & $530[0.84], 382[0.80], 309[2.30]$ & $\sim 800^{c}$ & 750 & & 110 & 0.26 & 0.56 \\
\hline $\mathrm{RuL}_{2} \mathrm{I}_{2}$ & $536[0.68], 384[0.66], 310[2.50]$ & $\sim 800^{c}$ & 755 & & 111 & 0.15 & 0.56 \\
\hline $\mathrm{RuL}_{2}\left(\mathrm{OH}_{2}\right)_{2}$ & 500 [1.19], 365 [1.09], 306 [4.90] & $\sim 800^{c}$ & 703 & & 165 & 0.30 & $0.58^{g}$ \\
\hline
\end{tabular}

${ }^{a}$ Isolated as neutral salts. ${ }^{b}$ Measured in $\mathrm{C}_{2} \mathrm{H}_{5} \mathrm{OH}$; molar extinction coefficient values $( \pm 10 \%)$ are given in square brackets. ${ }^{c}$ Very weak and broad. ${ }^{d}$ Measured in ethanol/methanol $(90 / 10, \mathrm{v} / \mathrm{v})$. ${ }^{e}$ Electrolyte was tetrafluoroborate tetrabutylammonium salt $/ \mathrm{C}_{2} \mathrm{H}_{4} \mathrm{OH}$; all potentials reported vs SCE. ${ }^{f}$ Measured in $\mathrm{CH}_{3} \mathrm{CN} .{ }^{g}$ Measured in $\mathrm{H}_{2} \mathrm{O}$ at $\mathrm{pH} 4.8$.

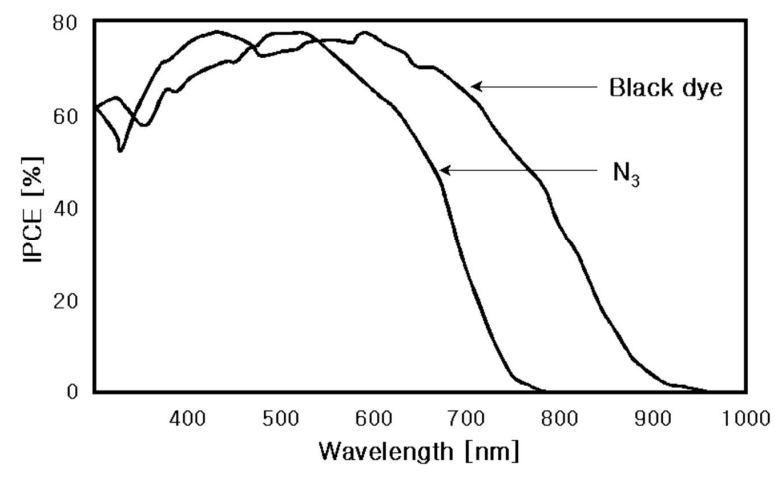

Figure 8. IPCE spectra of N3 and black dye [45].

from the $\mathrm{Ru}(\mathrm{II}) \mathrm{t} 2 \mathrm{~g}$ orbital to the $\pi^{*}$ orbital of the ligand. The $\pi^{*}$ orbital forms a molecular orbital, which lowers the $\mathrm{t} 2 \mathrm{~g}$ energy level of the metal and stabilizes it. Thus, the -NCS ligand was chosen, leading to the development of the N3 dye. Although an IPCE of $80-85 \%$ can be obtained with the $\mathrm{N} 3$ dye, there is a lack of light absorption at longer wavelengths in the visible region ( $\eta$ of $10 \%$ ) [42].

To improve on the performance of $\mathrm{N} 3$, the black dye was de- veloped $[43,44]$. In this dye, only one hydrogen (monoprotonated) on the polypyridyl ligand (tcterpy: $4,4^{\prime}, 4^{\prime \prime}$-tricarboxy-2, $2^{\prime}: 6^{\prime}, 2^{\prime \prime}$-terpyridine) is adsorbed to the metal oxide. This dye was fabricated to reduce intermolecular hydrogen bonds and thus reduce aggregation between dyes on the metal oxide surface. As shown by the IPCE results in Fig. 8, light absorption occurs, even in the near-infrared region ( $\eta$ of $10.4 \%$ ) [45]. The superior light absorption of the black dye results from a red shift of the MLCT. Despite having a lower molar extinction coefficient and smaller adsorption amount than the N3 dye, the black dye shows an improved PCE.

Among the three Ru-based dyes, N719 has the highest efficiency $[8,46]$. Dyes with carboxylic protons, such as N719, lose hydrogen when they are adsorbed on oxides. As a result, the surface of the metal oxide is positively charged and the Fermi energy level of the metal oxide is lowered. This change in energy level aids the adsorption of the dye on the metal oxide and facilitates electron transfer to the metal oxide in the excited state after light absorption. However, the results of the Nazeeruddin group show that although increasing the amount of hydrogen increases the photocurrent, the energy level difference between the Fermi energy level of the metal oxide and the redox energy level of the electrolyte is reduced, resulting in a lower $V_{\mathrm{oc}}$ and lower overall conversion [46]. Based on these contradictory results, 
<smiles></smiles>

Figure 9. Structure of Z-907.<smiles></smiles>

Figure 10. Structure of Z-910

N719 was developed as a high-efficiency DSSC dye ( $\eta$ of $11.18 \%$ ) [47].

Several further attempts have been made since the development of N719, one of which takes into account thermal stability, an important element of dye design. Amphiphilic heteroleptic sensitizers have both hydrophobic and hydrophilic groups. Z-907 (Fig. 9) shows improved thermal stability owing to the introduction of two hydrophobic alkyl groups into the bipyridyl ligands ( $\eta$ of $7.3 \%$ ) [48-53]. Amphiphilic polypyridyl dyes also have excellent thermal stability but have a lower molar extinction coefficient than N719. To compensate for this drawback, studies have been conducted to improve the molar extinction coefficient by increasing the conjugation length and thus increase absorption at longer wavelengths. The MLCT absorption bands of Z-910 (Fig. 10) are red-shifted relative to those of Z-907 and N719, resulting in a high efficiency ( $\eta$ of $10.2 \%$ ) $[39,54,55]$.

Among recently developed Ru dyes, PRT-22 reported by Wang et al. and CYC-B11 reported by Chen et al. have relatively high efficiencies of 11.16 and $11.50 \%$, respectively (Fig. 11) [56-58].

\section{Ru-free dyes}

Although Ru dyes have better conversion efficiencies than other dyes, they are limited by the high cost of Ru metal and their low molar extinction coefficients (typically $<2.50104 \mathrm{M}^{-1} \mathrm{~cm}^{-1}$ in the visible range). In contrast, $\mathrm{Ru}$-free dyes, which generally have higher molar extinction coefficients than Ru dyes (typically $>2.50104 \mathrm{M}^{-1} \mathrm{~cm}^{-1}$ in the visible range), are easy to synthesize and environmentally friendly. Owing to these advantages, Ru-free dyes been intensively studied. Furthermore, owing to the high molar extinction coefficients of $\mathrm{Ru}$-free dyes, a thinner $\mathrm{TiO}_{2}$ layer can be used, which further reduces charge loss and improves penetration of the electrolyte into the $\mathrm{TiO}_{2}$ pores [39].

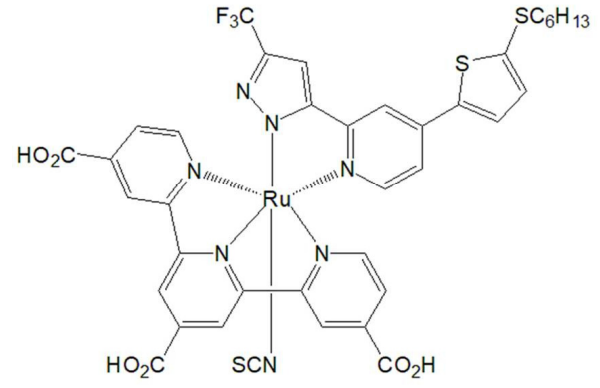

(a)

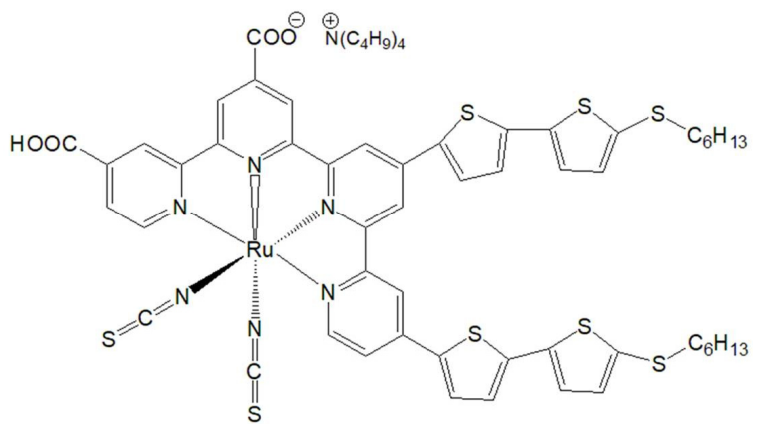

(b)

Figure 11. Structures of (a) PRT-22 and (b) CYC-B11.

Research on Ru-free dyes has led to studies of metals such as Os, $\mathrm{Pt}, \mathrm{Re}$, and Ir. Recently, using the zinc porphyrin-based dye YD2-o-C8 in a $\mathrm{Co}(\mathrm{II} / \mathrm{III})$ tris(bipyridyl) electrolyte, Yella et al. achieved a $\eta$ of $12.30 \%$ with the Y123 organic dye as an auxiliary sensitizer [59]. In the same electrolyte, the zinc porphyrin dye SM315 developed by Mathew et al. exhibited $\eta$ values of up to $13.00 \%$ (Fig. 12) [60].

\section{4) Metal-free organic dyes}

Donor- $\pi$-bridge-acceptor (D- $\pi$-A) dyes

Among Ru-free dyes, metal-free organic dyes have recently been in the spotlight. As these dyes do not contain metals, they can be synthesized at low cost without any resource constraints. As they are easily modifiable and have very high molar extinction coefficients in the charge transfer band, these dyes can show excellent light absorption properties [61]. However, there are still problems to be solved, as the efficiencies of metal-free organic dyes are still lower than those of organometallic dyes. Furthermore, owing to the nature of $\pi$-conjugated organic molecule, $\pi^{-} \pi$ stacking through intermolecular interactions is easy. However, for effective photocurrent generation, aggregation via $\pi^{-} \pi$ stacking between dyes adsorbed on the metal oxide should be prevented. In addition, owing to the intrinsic nature of organic compounds, the excited state lifetime is short and the absorption spectrum is not broad in the visible wavelength range; therefore, it is difficult to achieve light absorption over the entire wavelength range [39,62-65].

Figure 13 shows the basic structure of a D- $\pi$-A organic dye. These dyes consist of an electron donor group, a spacer group $(\pi$ -bridge/ $\pi$-conjugation) to increase the molar extinction coefficient in the UV region, an electron acceptor group, and an anchoring group (usually - $\mathrm{COOH}$ ) for adsorption on the metal oxide. Under incident sunlight, electrons are injected into the metal oxide from the donor 


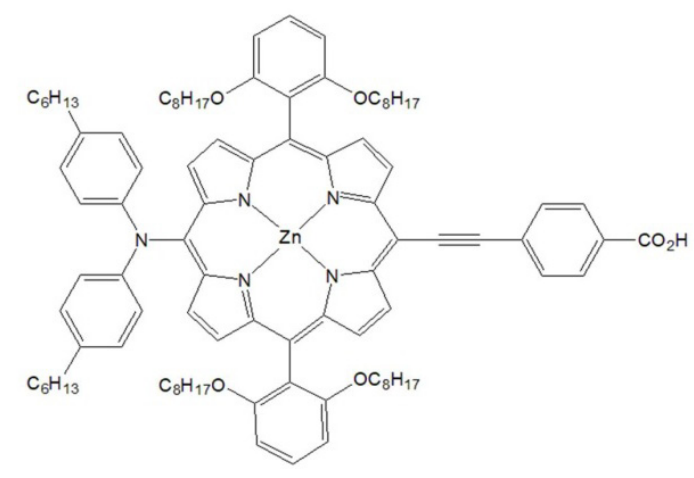

(a)

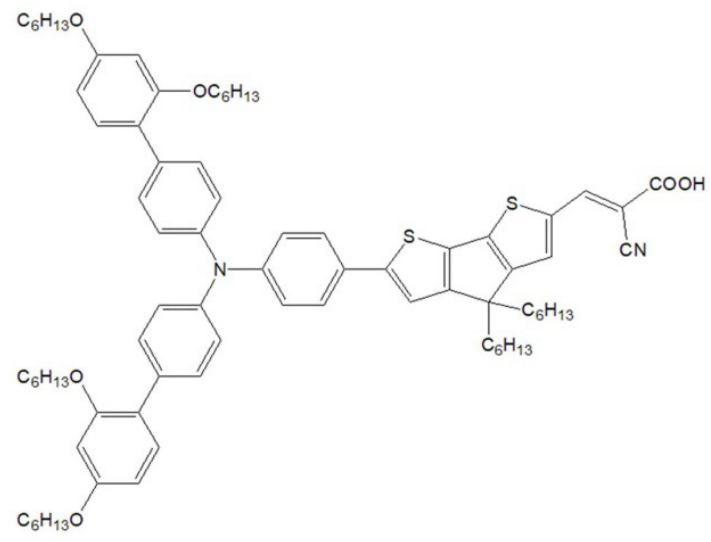

(b)

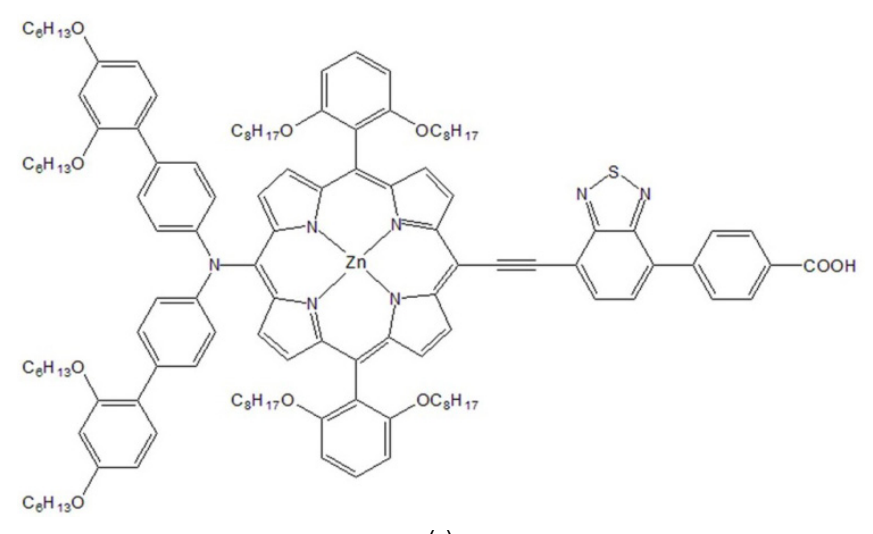

(c)

Figure 12. Structures of (a) YD2-o-C8, (b) Y123, and (c) SM315.

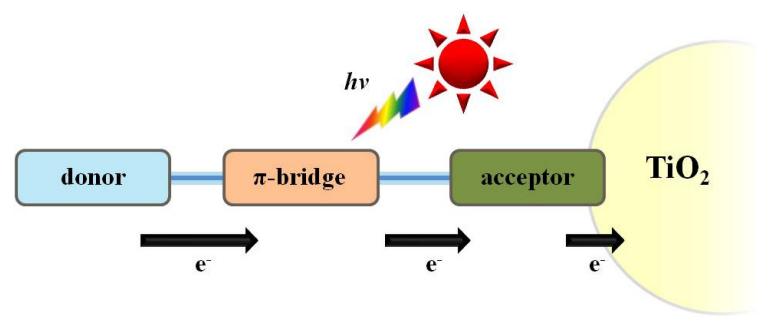

Figure 13. (Color online) Schematic diagram of donor- $\pi$-bridge-accepter organic dyes.

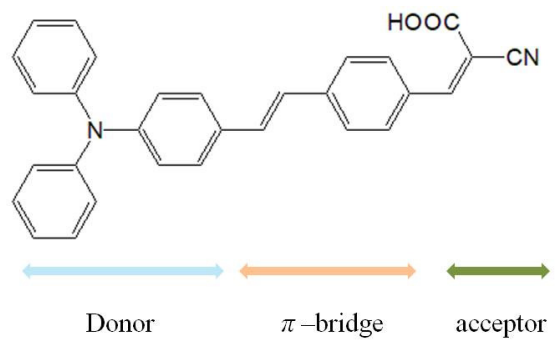

Figure 14. (Color online) Structure of TA-St-CA [66]

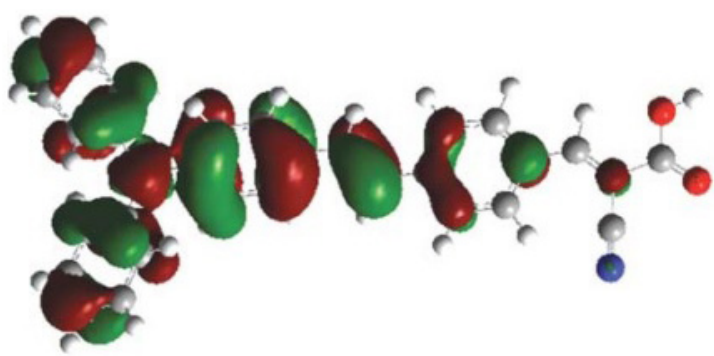

(a)

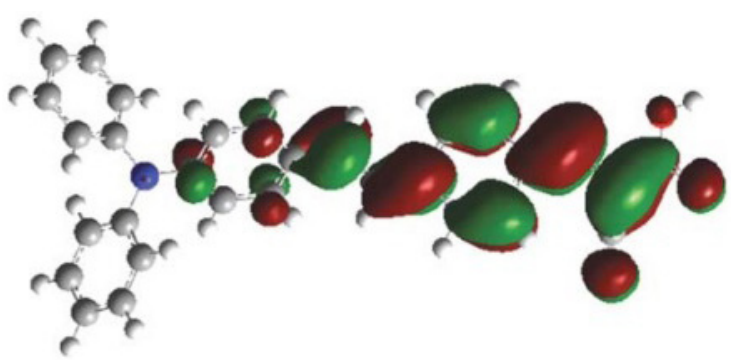

(b)

Figure 15. (Color online) Frontier molecular orbital diagram of TA-St-CA. (a) HOMO and (b) LUMO optimized using time-dependent density functional theory at the $B 3 L Y P / 6-31+G(d)$ level of theory [66].

via the $\pi$-bridge through the acceptor.

Figure 14 shows the structure of TA-St-CA, a D- $\pi$-A organic dye developed by Hwang et al., and Fig. 15 shows the frontier molecular orbitals. In the absence of light, the electron density of the dye is concentrated on the diphenylaniline donor group rather than the acceptor group (HOMO), but under incident light, the electron density moves toward the acceptor group (LUMO). The electrons move back to the metal oxide through the carboxyl group. Notably, the nonplanar diphenylaniline moiety in this dye largely prevents $\pi^{-} \pi$ stacking. Using this dye, an $\eta$ value of $9.1 \%$ was achieved, whereas reference material N719 exhibited an $\eta$ value of $10.1 \%$ under similar conditions [66].

Recently, a parallel tandem DSSC device was fabricated by combining a metal-free organic dye with a porphyrin dye to get an extremely high efficiency of $>14 \%$. However, this system exhibited poor stability [67].

Donor-acceptor- $\pi$-bridge-acceptor (D-A- $\pi$-A) dyes

Recently, organic dyes with D-A- $\pi$-A structures have been studied [68-70]. Zhu et al. suggested that the D-A- $\pi$-A structure can enhance optical stability by introducing an additional electron-withdrawing 
group acceptor into the $\pi$-bridge [68]. Based on this, Mane et al. proposed a new D-A- $\pi$-A structure using a 1,3,4-oxadiazole ring that is not only chemically and thermally stable but also has a high photoluminescence quantum yield [70]. The characteristics of dyes with a D-A- $\pi$-A structure were studied by comparing three OD dyes
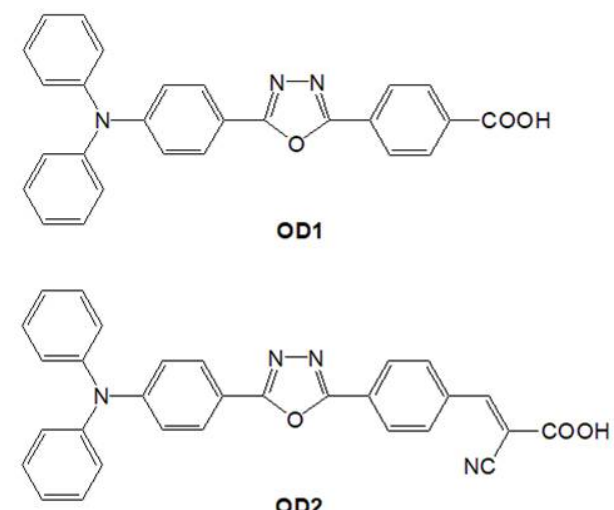

OD2

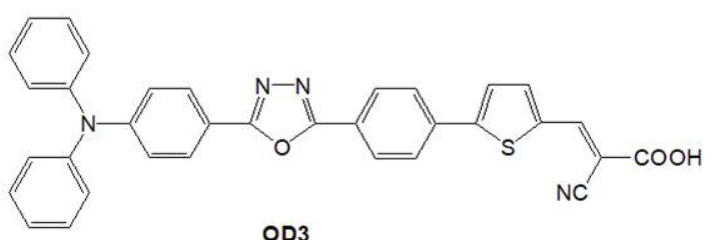

OD3

Figure 16. Structures of OD1, OD2, and OD3.
(OD1, OD2, and OD3). The structures and synthesis process are shown in Figs. 16 and 17.

These oxadiazole dyes are known to have good absorbance in the visible region and good charge transport capacity. As shown in Fig. 16, in OD1 and OD3, the distance between the two acceptors is different (secondary oxadiazole acceptor and carboxylic acid or cyanoacrylic acid acceptor). Furthermore, OD1 and OD2 have different anchoring groups (carboxylic acid and cyanoacrylic acid, respectively). Generally, cyanoacrylic acid as an acceptor can reduce the band gap energy between the HOMO and LUMO. OD3 has cyanoacrylic acid as an anchoring group and a thiophene group to extend the $\pi$-bridge and thus extend the absorption to longer wavelengths. Figure 18 shows the energy level diagrams of the OD dyes. As the $\pi$-conjugation length decreases, the band gap between the HOMO and LUMO decreases, which in turn causes a red shift of the absorption band (Fig. 19). Furthermore, decreasing the energy of LUMO facilitates electron injection into the $\mathrm{TiO}_{2}$ conduction band [70]. Figure 20 shows the frontier molecular orbitals of each OD dye. In the HOMO, the electron density is concentrated on the donor triphenylamine moiety, whereas in the LUMO, the electron density is concentrated on the acceptor oxadiazole and acceptor acid group.

As shown by the $J-V$ curve of the OD dyes (Fig. 21), OD3 exhibits the highest $J_{\mathrm{sc}}$ value. Moreover, the $\eta$ value calculated for OD3 was the highest (2.72\%; Table II). As a result, the efficiency of OD3 was the highest. The comparison of the three OD dyes revealed that a longer $\pi$-bridge resulted in a red shift of the absorption band and increased charge separation. Based on these results, Mane et al. concluded that the length of the $\pi$-bridge is the most important factor for improving the photoelectric efficiency [70].
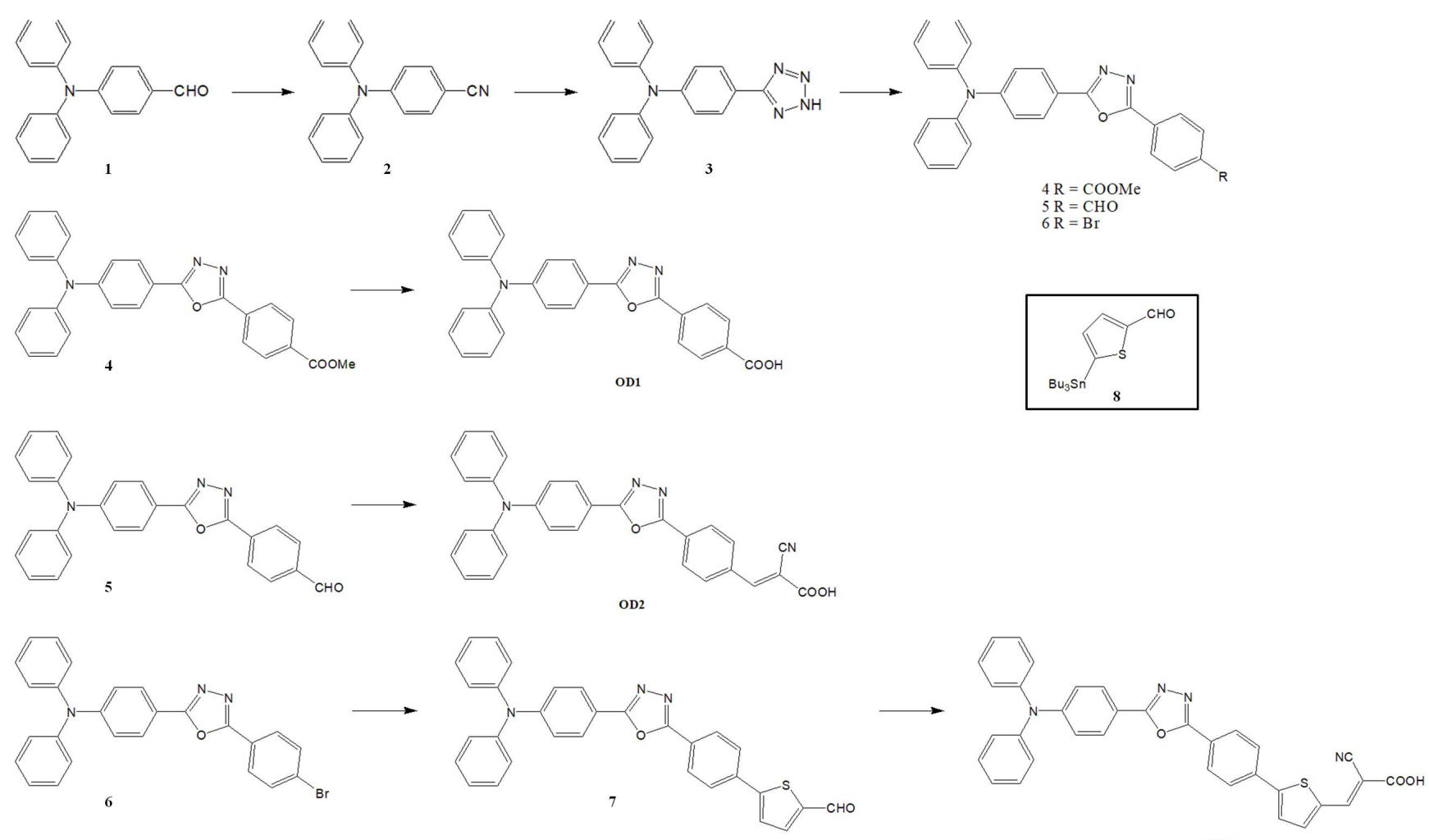

OD3

Figure 17. Schematic diagram of the synthesis of $O D$ dyes. 


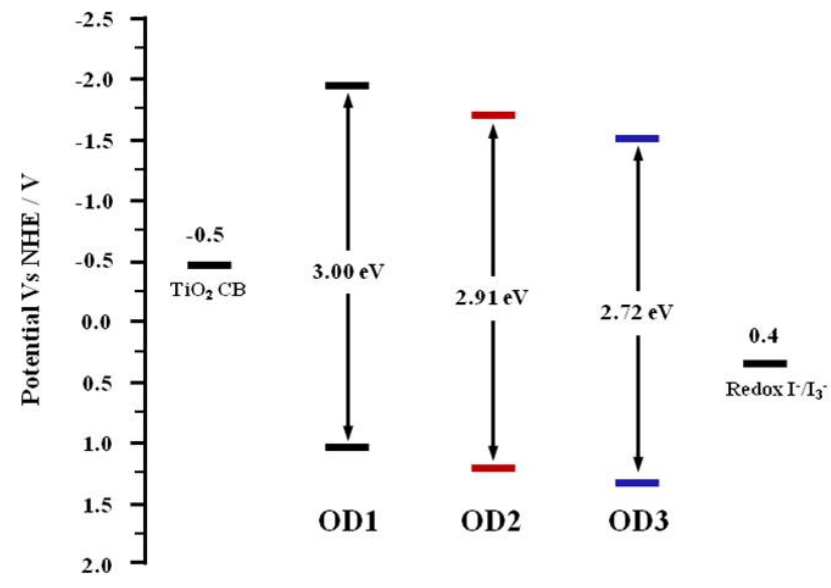

Figure 18. (Color online) Energy level diagrams of OD dyes [70].

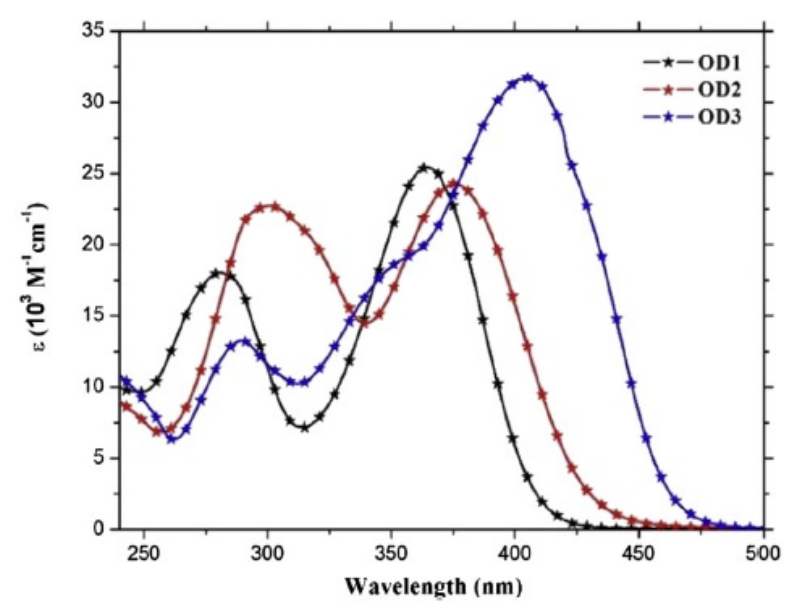

Figure 19. (Color online) UV-vis spectra of OD dyes (measured in ethanol) [70]

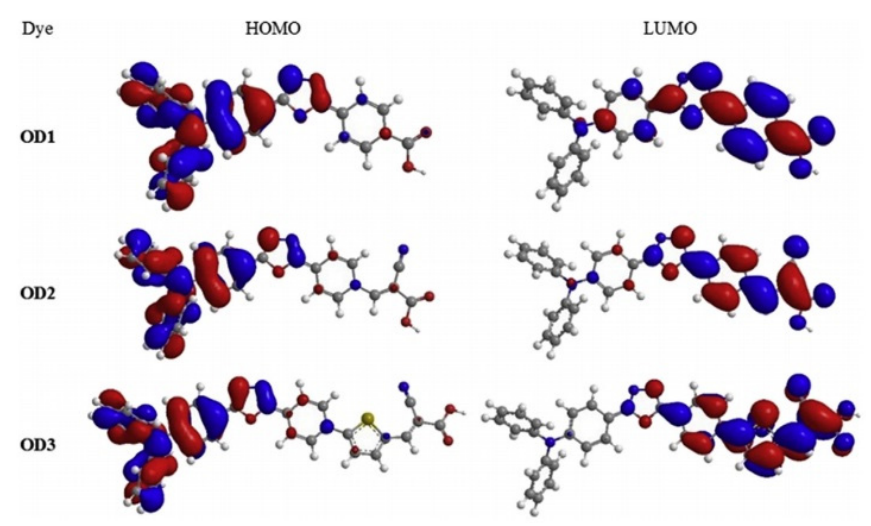

Figure 20. (Color online) Frontier molecular orbital diagrams of OD dyes [70].

\section{Donor-free dyes}

Another type of sensitizer that has been studied recently is donor-free dyes. In general, the HOMO of a dye is located on the donor and $\pi$-bridge, whereas the LUMO is located on the acceptor and anchoring groups. However, omitting the donor has been shown to improve the photoelectric properties.

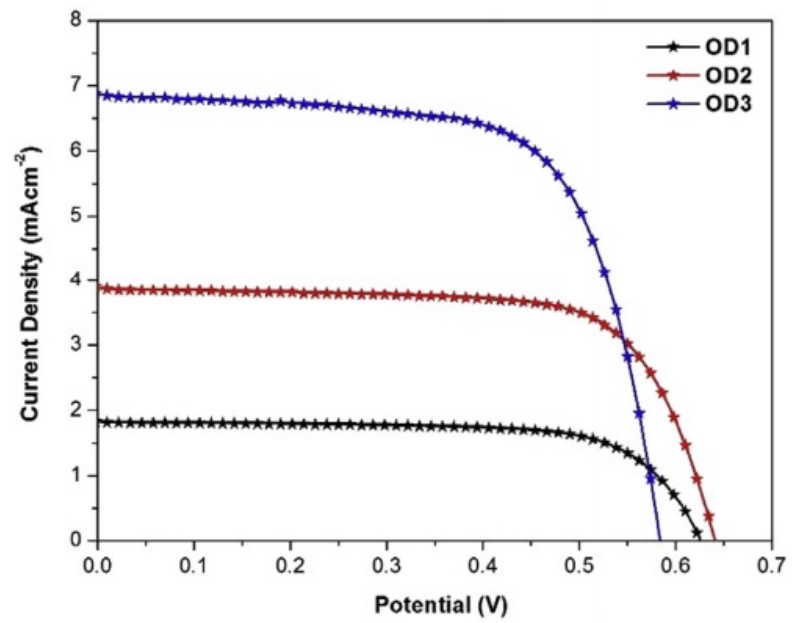

Figure 21. (Color online) $J-V$ curves of OD dyes [70].

Table II. Photoelectric properties of OD dyes in DSSCs [70].

\begin{tabular}{ccccc}
\hline Dye & $\begin{array}{c}J_{\text {sc }} \\
\left(\mathrm{mA} \mathrm{cm}^{-2}\right)\end{array}$ & $\begin{array}{c}V_{\text {oc }} \\
(\mathrm{V})\end{array}$ & $\begin{array}{c}f f \\
(\%)\end{array}$ & $\begin{array}{c}\eta \\
(\%)\end{array}$ \\
\hline OD1 & 1.82 & 0.62 & 71 & 0.80 \\
OD2 & 3.88 & 0.64 & 71 & 1.76 \\
OD3 & 6.87 & 0.58 & 68 & 2.72 \\
\hline
\end{tabular}

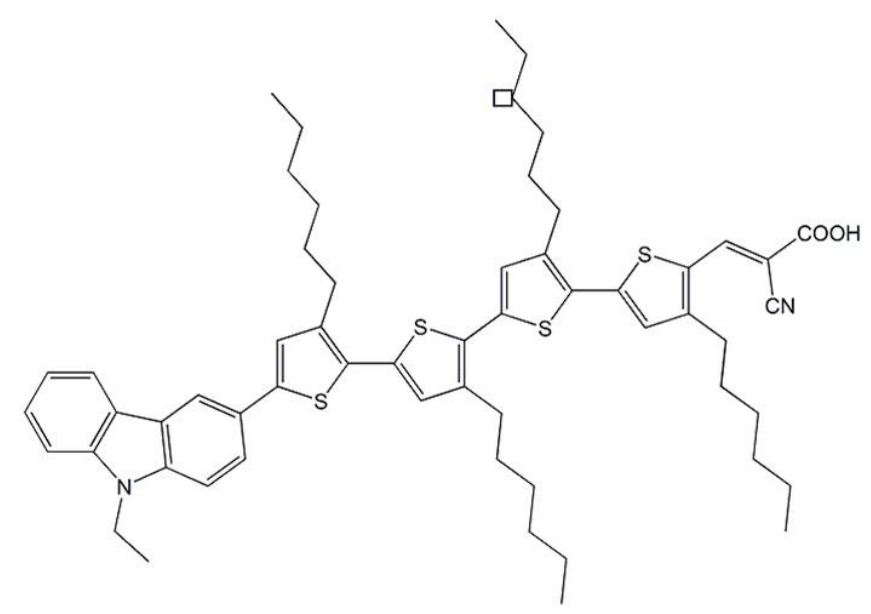

Figure 22. Structure of MK-2.

Abate et al. compared the MK-2 dye (Fig. 22) with its donor-free structure 5T, a cyanoacrylic end-functionalized oligo (3-hexylthiophene) dye [71]. 5T has a higher $V_{\mathrm{oc}}$ value than MK-2, but the $J_{\mathrm{sc}}$ values of the two dyes are similar. Therefore, removing the donor resulted in a higher overall efficiency, with $\eta$ values of $4.4 \%$ for $5 \mathrm{~T}$ and $2.8 \%$ for MK-2.

$\mathrm{Hu}$ et al. furthered this work by studying another donor-free dye, 6T, which has a thiophene group [72]. Figure 23 shows the structures and synthesis processes of $5 \mathrm{~T}$ and $6 \mathrm{~T}$ dyes. Neither structure contains a donor, and $6 \mathrm{~T}$ has one more thiophene group than 5T. Figure 24 shows the absorption spectra of $5 \mathrm{~T}$ and $6 \mathrm{~T}$. The absorption wavelength of $6 \mathrm{~T}$ is slightly shifted to longer wavelengths, 

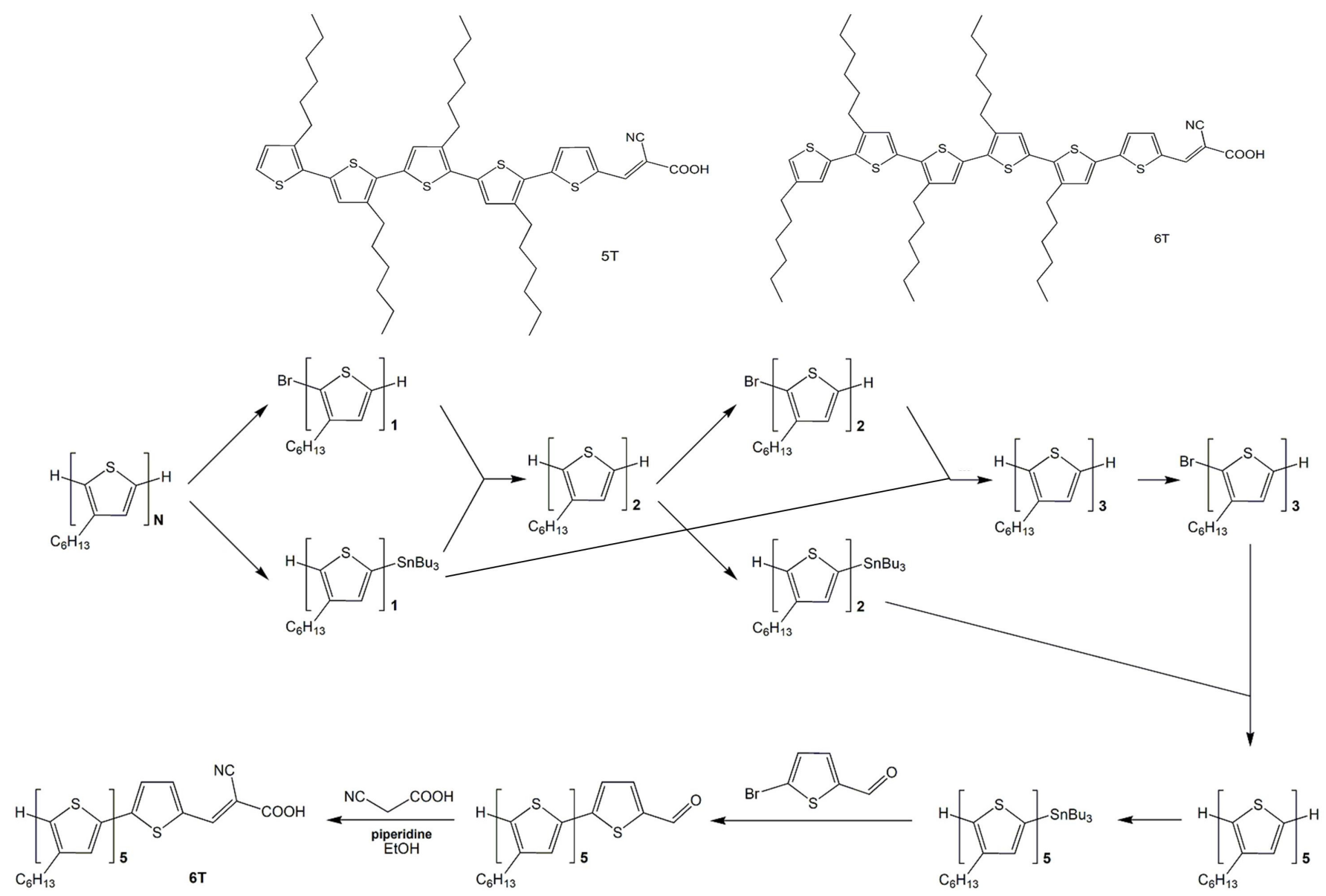

Figure 23. Structures of $5 \mathrm{~T}$ and $6 \mathrm{~T}$ and schematic diagram of the synthesis of these dyes.

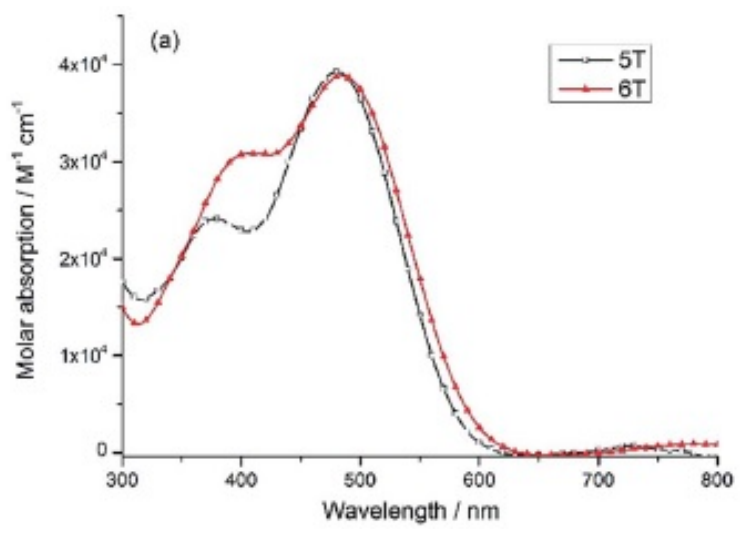

Figure 24. (Color online) UV-vis spectra of $5 \mathrm{~T}$ and $6 \mathrm{~T}\left(2 \times 10^{-6} \mathrm{M}\right.$ in dichloromethane) [72].

as is generally expected when the length of the $\pi$-bridge is increased, which results in an increase in $V_{\text {oc. }}$. Figure 25 shows a comparison of the $J-V$ curves of the two donor-free dyes with those of N719 and MK-2. N719 has the highest $J_{\text {sc }}$ value because N719 has the widest absorption range. Table III summarizes the photoelectric characteristics of these dyes. The $\eta$ value of $5 \mathrm{~T}$ was $7.64 \%$, whereas that of $6 \mathrm{~T}$ was $7.07 \%$. 6T shows a higher $V_{\text {oc }}$ value than $5 \mathrm{~T}$, but its efficiency was

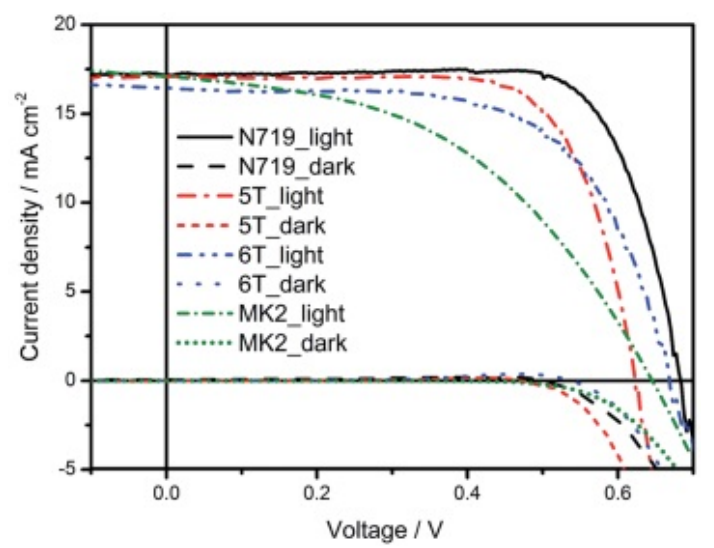

Figure 25. J-V curves of N719, MK-2, 5T, and 6T [72].

Table III. Photoelectric properties of N719, 5T, and 6T dyes in DSSCs [72].

\begin{tabular}{cccccc}
\hline Dye & $\begin{array}{c}J_{\text {sc }} \\
\left(\mathrm{mA} \mathrm{cm}^{-2}\right)\end{array}$ & $\begin{array}{c}V_{\mathrm{oc}} \\
(\mathrm{V})\end{array}$ & $\begin{array}{c}f f \\
(\%)\end{array}$ & $\begin{array}{c}\eta \\
(\%)\end{array}$ & $\begin{array}{c}\text { Dye loading } \\
\left(\times 10^{7} \mathrm{~mol} \mathrm{~cm}^{-2}\right)\end{array}$ \\
\hline $\mathrm{N} 719$ & 17.48 & 0.68 & 74.7 & 8.89 & 3.04 \\
5T & 17.15 & 0.62 & 72.0 & 7.64 & 5.09 \\
6T & 16.85 & 0.67 & 62.8 & 7.07 & 5.38 \\
\hline
\end{tabular}


Table IV. (Color online) Characteristics of N719 and various natural dyes.

Dye name and chemical information

Synthetic dye: Ruthenium 535-bisTBA (N719)

Molecular formula: $\mathrm{C}_{58} \mathrm{H}_{86} \mathrm{O}_{8} \mathrm{~N}_{8} \mathrm{~S}_{2} \mathrm{Ru}$

Molecular weight: 1187.7

Natural dye $1(\mathrm{Y})$

Saffron (curcumin)

Molecular formula: $\mathrm{C}_{21} \mathrm{H}_{20} \mathrm{O}_{6}$

Molecular weight: 368.38<smiles>COc1cc(/C=C/C(=O)CC(=O)/C=C/c2ccc(O)c(O)c2)ccc1O</smiles>

Natural dye 2 (S)

Black tea (caffeine)

Molecular formula: $\mathrm{C}_{8} \mathrm{H}_{10} \mathrm{~N}_{4} \mathrm{O}_{2}$

Molecular weight: 194.19

$$
\text { 型 }
$$

Natural dye 3 (B)

Beet ( $\beta$-carotene and betalain)

Molecular formula: $\mathrm{C}_{40} \mathrm{H}_{56}$

Molecular weight: 536.87

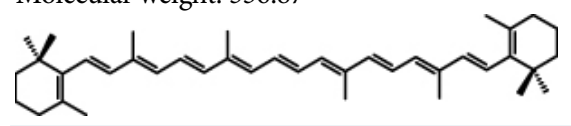

Black tea is fermented from young leaves of the tea tree, dried, and boiled in water. It is mainly produced in China, Japan, India, and Sri Lanka. Caffeine, which shows remarkable physiological effects, obtained from substances such as tea, coffee, guarana, maté, cola, and cacao.
$\beta$-Carotene is a carotenoid pigment found in vegetables such as carrots and beets. It is known to be a precursor of vitamin A and to exhibit antioxidant activity, skin aging prevention, and visual stimulation. Beets, which are rich in riboflavin, iron, and vitamins $\mathrm{A}-\mathrm{C}$, as well as anthocyanin, have anticancer effects and can remove active oxygen species and cholesterol. The roots of beets contain betalain and sugar as well as a large amount of vitamin A and potassium. In particular, betanin, the most well-known betalain, has an antioxidant effect that delays aging and can increase stress resistance.

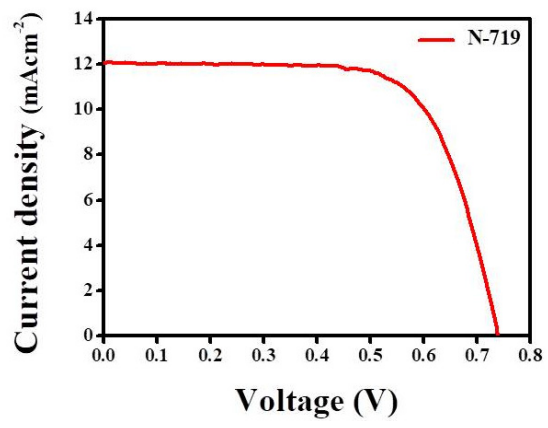

(a)

Figure 26. (Color online) J-V curves of (a) N719-based DSSC and (b) natural-dye-based DSSCs.

lower owing to its low $J_{\mathrm{sc}}$ and $f f$ values. As the number of thiophene groups increases, the amount of $\pi^{-} \pi$ interactions increases, resulting in greater aggregation of the dyes on the $\mathrm{TiO}_{2}$ surface, which will prevent diffusion of the electrolyte into mesoporous $\mathrm{TiO}_{2}$ and thus lengthen the charge transport time. In other words, the longer charge transport time in $6 \mathrm{~T}$ implies that more trap states exist and the resistance is higher, resulting in lower $J_{\mathrm{sc}}$ and $f f$ values $[30,73]$.

\section{5) Natural dyes}

Attempts have recently been made to produce environmentally friendly DSSCs using natural dyes that can be extracted from readily available materials such as flowers and plants [74]. Our lab has also fabricated DSSCs using natural dyes such as turmeric and saffron (curcumin), black tea (caffeine), and beet ( $\beta$-carotene and betalain) to test the applicability of DSSCs as environmentally friendly solar cells [unpublished data]. Table IV summarizes the characteristics of the dyes used for the natural-dye-based DSSCs and, for comparison, the properties of the Ru-based dye N719. As shown in Fig. 26, the efficiencies of the natural-dye-based DSSCs are much lower than that of a commercial N719-based DSSC. Nevertheless, this work showed that environmentally friendly solar cells could be developed. The relative cell efficiencies decreased in the order of turmeric $(\mathrm{Y})$, black tea (S), and beet (B), and in all cases, the efficiency increased as the dye adsorption amount increased (see also Table V). 
Table V. Device characteristics of N719-based and natural-dye-based DSSCs.

\begin{tabular}{ccccc}
\hline Dye & $\begin{array}{c}J_{\mathrm{sc}} \\
\left(\mathrm{mA} \mathrm{cm}^{-2}\right)\end{array}$ & $\begin{array}{c}V_{\mathrm{oc}} \\
(\mathrm{V})\end{array}$ & $\begin{array}{c}f f \\
(\%)\end{array}$ & $\begin{array}{c}\eta \\
(\%)\end{array}$ \\
\hline N719 & 12.130 & 0.7357 & 67.21 & 5.999 \\
Y-1 & 0.4865 & 0.5352 & 73.19 & 0.191 \\
Y-2 & 0.4558 & 0.5281 & 72.95 & 0.176 \\
Y-3 & 0.4344 & 0.5319 & 73.06 & 0.169 \\
S-1 & 0.2974 & 0.5183 & 73.26 & 0.113 \\
S-2 & 0.3508 & 0.5132 & 72.25 & 0.131 \\
S-3 & 0.3247 & 0.5172 & 73.39 & 0.123 \\
B-1 & 0.2221 & 0.4645 & 66.09 & 0.068 \\
B-2 & 0.2089 & 0.4666 & 65.78 & 0.064 \\
B-3 & 0.2011 & 0.4694 & 65.29 & 0.062 \\
\hline
\end{tabular}

\section{Conclusions}

Herein, the principles of various types of metal-complex-based dyes were reviewed. In addition, the necessity for metal-free organic dyes was discussed, and the possibility of improving efficiency by using $\mathrm{D}-\pi-\mathrm{A}, \mathrm{D}-\mathrm{A}-\pi-\mathrm{A}$, or donor-free dyes was examined. Very recently, studies have been conducted on bridged dyes with extended $\pi$-conjugation that use materials such as anthracene, tetracene, and pentacene as the $\pi$-bridge $[65,75]$. As another approach, porphyrin dyes, quantum dot sensitizers, and perovskite-based sensitizers have been examined $[76,77]$. However, more detailed and systematic studies on the effects of molecular structural engineering on the photophysical and electrochemical properties, photovoltaic parameters, and efficiency of DSSCs are still required [78].

Since the development of the DSSC by Grätzel in 1991, many studies have examined various possibilities for improving DSSC performance, but the efficiencies of DSSCs are still lower than those of other types of solar cell devices. However, considering the advantages of DSSCs for a wide range of applications, such as economic efficiency and the ability to make transparent devices of various colors, research in this area remains valuable. To this end, in-depth research on existing materials should be continued and further research on new devices should be conducted along with an ongoing search for new materials.

\section{References}

[1] S. H. Jung, K. J. Hwang, S. W. Kang, H. G. Jeong, S. I. Kim, and J. W. Lee, J. Korean Ind. Eng. Chem. 20, 227 (2009).

[2] B. O'Regan and M. Grätzel, Nature 353, 737 (1991).

[3] M. Grätzel, Nature 414, 338 (2001).

[4] Y. M. Lee, S. H. Nam, and J. H. Boo, Appl. Sci. Converg. Technol. 24, 289 (2015).

[5] (a) H. Seo, Y. Wang, D. Ichida, G. Uchida, N. Itagaki, K. Koga, M. Shiratani, S. H. Nam, and J. H. Boo, Jpn. J. Appl. Phys. 52, 11NM02 (2013); (b) H. Seo, S. H. Nam, N. Itagaki, K. Koga, M. Shiratani, and J. H. Boo, Electron. Mater. Lett. 12, 530 (2016).

[6] S. H. Nam, D. W. Ju, and J. H. Boo, J. Nanosci. Nanotechnol. 14, 9406 (2014).

[7] (a) M. Grätzel, J. Photochem. Photobiol. C 4, 145 (2003); (b) M.
Grätzel, J. Photochem. Photobiol. A 164, 3 (2004).

[8] M. Grätzel, Inorg. Chem. 44, 6841 (2005).

[9] R. Komiya, A. Fukui, N. Murofushi, N. Koide, R. Yamanaka, and H. Katayama, Technical Digest, 21st International Photovoltaic Science and Engineering Conference, (Fukuoka, Japan, November 28-December 2, 2011), 2C-5O-08.

[10] M. A. Green, E. D. Dunlop, D. H. Levi, J. Hohl-Ebinger, M. Yoshita, and A. W. Y. Ho-Baillie, Prog. Photovoltaics 27, 565 (2019).

[11] W. Y. Rho, H. Jeon, H. S. Kim, W. J. Chung, J. S. Suh, and B. H. Jun, J. Nanomater. 2015, 247689 (2015).

[12] T. Kawashima, T. Ezure, K. Okada, H. Matsui, K. Goto, and N. Tanabe, J. Photochem. Photobiol. A 164, 199 (2004).

[13] W. Sharmoukh and N. K. Allam, ACS Appl. Mater. Interfaces 4, 4413 (2012).

[14] X. Yang, M. Yanagida, and L. Han, Energy Environ. Sci. 6, 54 (2013).

[15] D. W. Zhang, X. D. Li, H. B. Li, S. Chen, Z. Sun, X. J. Yin, and S. M. Huang, Carbon 49, 5382 (2011).

[16] (a) Y. Xue, J. Liu, H. Chen, R. Wang, D. Li, J. Qu, and L. Dai, Angew. Chem. Int. Ed. 51, 12124 (2012); (b) K. B. Kim, Appl. Sci. Converg. Technol. 26, 16 (2017).

[17] G. Boschloo and A. Hagfeldt, Acc. Chem. Res. 42, 1819 (2009).

[18] A. Hagfeldt, G. Boschloo, L. Sun, L. Kloo, and H. Pettersson, Chem. Rev. 110, 6595 (2010).

[19] S. S. Bhande, D. V. Shinde, K. K. Tehare, S. A. Patil, R. S. Mane, M. Naushad, Z. A. Alothman, K. N. Hui, and S. H. Han, J. Photochem. Photobiol. A 295, 64 (2014).

[20] S. H. Nam, J. S. Hyun, and J. H. Boo, Mater. Res. Bull. 47, 2717 (2012).

[21] H. Seo, D. Ichida, S. Hashimoto, N. Itagaki, K. Koga, M. Shiratani, S. H. Nam, and J. H. Boo, J. Nanosci. Nanotechnol. 16, 4875 (2016).

[22] N. G. Park, J. Korean Ind. Eng. Chem. 15, 265 (2004).

[23] Y. M. Lee, D. I. Kim, K. H. Hwang, S. H. Nam, and J. H. Boo, Electron. Mater. Lett. 12, 512 (2016).

[24] T. N. Murakami, S. Ito, Q. Wang, M. K. Nazeeruddin, T. Bessho, I. Cesar, P. Liska, R. Humphry-Baker, P. Comte, P. Péchy, and M. Grätzel, J. Electrochem. Soc. 153, A2255 (2006).

[25] R. Jia, J. Chen, J. Zhao, J. Zheng, C. Song, L. Li, and Z. Zhu, J. Mater. Chem. 20, 10829 (2010).

[26] Z. Yang, T. Chen, R. He, G. Guan, H. Li, L. Qiu, and H. Peng, Adv. Mater. 23, 5436 (2011).

[27] J. Han, H. Kim, D. Y. Kim, S. M. Jo, and S. Y. Jang, ACS Nano 4, 3503 (2010).

[28] H. Choi, H. Kim, S. Hwang, Y. Han, and M. Jeon, J. Mater. Chem. 21, 7548 (2011).

[29] J. D. Roy-Mayhew, D. J. Bozym, C. Punckt, and I. A. Aksay, ACS Nano 4, 6203 (2010).

[30] J. G. Rowley, B. H. Farnum, S. Ardo, and G. J. Meyer, J. Phys. Chem. Lett. 1, 3132 (2010).

[31] S. Ardo and G. J. Meyer, Chem. Soc. Rev. 38, 115 (2009).

[32] J. M. Gardner, M. Abrahamsson, B. H. Farnum, and G. J. Meyer, J. Am. Chem. Soc. 131, 16206 (2009).

[33] S. Yanagida, Y. Yu, and K. Manseki, Acc. Chem. Res. 42, 1827 (2009).

[34] Z. S. Wang, K. Sayama, and H. Sugihara, J. Phys. Chem. B 109, 22449 (2005). 
[35] M. Wang, N. Chamberland, L. Breau, J. E. Moser, R. Humphry-Baker, B. Marsan, S. M. Zakeeruddin, and M. Grätzel, Nat. Chem. 2, 385 (2010).

[36] Z. Ning, Q. Zhang, W. Wu, and H. Tian, J. Organomet. Chem. 694, 2705 (2009).

[37] Z. Yu, N. Vlachopoulos, M. Gorlov, and L. Kloo, Dalton Trans. 40, 10289 (2011).

[38] J. Gong, J. Liang, and K. Sumathy, Renewable Sustainable Energy Rev. 16, 5848 (2012).

[39] J. Ko and C. Lee, Polym. Sci. Technol. 17, 436 (2006).

[40] H. Kisserwan and T. H. Ghaddar, Inorg. Chim. Acta 363, 2409 (2010).

[41] M. K. Nazeeruddin, A. Kay, I. Rodicio, R. Humphry-Baker, E. Müller, P. Liska, N. Vlachopoulos, and M. Grätzel, J. Am. Chem. Soc. 115, 6382 (1993).

[42] D. Wei, Int. J. Mol. Sci. 11, 1103 (2010).

[43] M. K. Nazeeruddin, P. Péchy, and M. Grätzel, Chem. Commun. 1705 (1997).

[44] M. K. Nazeeruddin, P. Péchy, T. Renouard, S. M. Zakeeruddin, R. Humphry-Baker, P. Comte, P. Liska, L. Cevey, E. Costa, V. Shklover, L. Spiccia, G. B. Deacon, C. A. Bignozzi, and M. Grätzel, J. Am. Chem. Soc. 123, 1613 (2001).

[45] A. Hagfeldt and M. Grätzel, Acc. Chem. Res. 33, 269 (2000).

[46] M. K. Nazeeruddin, F. De Angelis, S. Fantacci, A. Selloni, G. Viscardi, P. Liska, S. Ito, B. Takeru, and M. Grätzel, J. Am. Chem. Soc. 127, 16835 (2005).

[47] T. Funaki, M. Yanagida, N. Onozawa-Komatsuzaki, K. Kasuga, Y. Kawanishi, and H. Sugihara, Inorg. Chim. Acta 362, 2519 (2009).

[48] P. Wang, S. M. Zakeeruddin, I. Exnar, and M. Grätzel, Chem. Commun. 2972 (2002).

[49] P. Wang, S. M. Zakeeruddin, J. E. Moser, M. K. Nazeeruddin, T. Sekiguchi, and M. Grätzel, Nat. Mater. 2, 402 (2003).

[50] P. Wang, S. M. Zakeeruddin, R. Humphry-Baker, J. E. Moser, and M. Grätzel, Adv. Mater. 15, 2101 (2003).

[51] P. Wang, S. M. Zakeeruddin, P. Comte, R. Charvet, R. Humphry-Baker, and M. Grätzel, J. Phys. Chem. B 107, 14336 (2003).

[52] P. Wang, S. M. Zakeeruddin, R. Humphry-Baker, and M. Grätzel, Chem. Mater. 16, 2694 (2004).

[53] N. Onozawa-Komatsuzaki, M. Yanagida, T. Funaki, K. Kasuga, K. Sayama, and H. Sugihara, Sol. Energy Mater. Sol. Cells 95, 310 (2011).

[54] P. Wang, S. M. Zakeeruddin, J. E. Moser, R. Humphry-Baker, P. Comte, V. Aranyos, A. Hagfeldt, M. K. Nazeeruddin, and M. Grätzel, Adv. Mater. 16, 1806 (2004).

[55] D. Kuang, S. Ito, B. Wenger, C. Klein, J. E. Moser, R. Humphry-Baker, S. M. Zakeeruddin, and M. Grätzel, J. Am. Chem. Soc. 128, 4146 (2006).

[56] S. W. Wang, C. C. Chou, F. C. Hu, K. L. Wu, Y. Chi, J. N. Clifford, E. Palomares, S. H. Liu, P. T. Chou, T. C. Wei, and T. Y. Hsiao, J. Mater. Chem. A 2, 17618 (2014).

[57] C. Y. Chen, M. Wang, J. Y. Li, N. Pootrakulchote, L. Alibabaei, C. Ngoc-le, J. D. Decoppet, J. H. Tsai, C. Grätzel, C. G. Wu, S. M. Zakeeruddin, and M. Grätzel, ACS Nano 3, 3103 (2009).

[58] (a) L. Han, A. Islam, H. Chen, C. Malapaka, B. Chiranjeevi, S. Zhang, X. Yang, and M. Yanagida, Energy Environ. Sci. 5, 6057
(2012); (b) C. P. Lee, R. Y. Y. Lin, L. Y. Lin, C. T. Li, T. C. Chu, S. S. Sun, J. T. Lin, and K. C. Ho, RSC Adv. 5, 23810 (2015).

[59] A. Yella, H. W. Lee, H. N. Tsao, C. Yi, A. K. Chandiran, M. K. Nazeeruddin, E. W. G. Diau, C. Y. Yeh, S. M. Zakeeruddin, and M. Grätzel, Science 334, 629 (2011).

[60] S. Mathew, A. Yella, P. Gao, R. Humphry-Baker, B. F. E. Curchod, N. Ashari-Astani, I. Tavernelli, U. Rothlisberger, M. K. Nazeeruddin, and M. Grätzel, Nat. Chem. 6, 242 (2014).

[61] Y. S. Yen, H. H. Chou, Y. C. Chen, C. Y. Hsu, and J. T. Lin, J. Mater. Chem. 22, 8734 (2012).

[62] T. Kitamura, M. Ikeda, K. Shigaki, T. Inoue, N. A. Anderson, X. Ai, T. Lian, and S. Yanagida, Chem. Mater. 16, 1806 (2004).

[63] K. Hara, M. Kurashige, Y. Dan-oh, C. Kasada, A. Shinpo, S. Suga, K. Sayama, and H. Arakawa, New J. Chem. 27, 783 (2003).

[64] H. Meier, Z. S. Huang, and D. Cao, J. Mater. Chem. C 5, 9828 (2017).

[65] (a) J. M. Ji, H. Zhou, and H. K. Kim, J. Mater. Chem. A 6, 14518 (2018); (b) H. Chen, G. Lyu, Y. Yue, T. Wang, D. P. Li, H. Shi, J. Xing, J. Shao, R. Zhang, and J. Liu, J. Mater. Chem. C 7, 7249 (2019).

[66] S. Hwang, J. H. Lee, C. Park, H. Lee, C. Kim, C. Park, M. H. Lee, W. Lee, J. Park, K. Kim, N. G. Park, and C. Kim, Chem. Commun. 46, 4887 (2007).

[67] (a) K. Kakiage, Y. Aoyama, T. Yano, K. Oya, J. Fujisawa, and M. Hanaya, Chem. Commun. 51, 15894 (2015); (b) Y. K. Eom, S. H. Kang, I. T. Choi, Y. Yoo, J. Kim, and H. K. Kim, J. Mater. Chem. A 5, 2297 (2017).

[68] (a) W. Zhu, Y. Wu, S. Wang, W. Li, X. Li, J. Chen, Z. Wang, and H. Tian, Adv. Funct. Mater. 21, 756 (2011); (b) Y. Wu, W. H. Zhu, S. M. Zakeeruddin, and M. Grätzel, ACS Appl. Mater. Interfaces 7, 9307 (2015).

[69] X. Li, B. Xu, P. Liu, Y. Hu, L. Kloo, J. Hua, L. Sun, and H. Tian, J. Mater. Chem. A 5, 3157 (2017).

[70] S. B. Mane, C. F. Cheng, A. A. Sutanto, A. Datta, A. Dutta, and C. H. Hung, Tetrahedron 71, 7977 (2015).

[71] A. Abate, M. Planells, D. J. Hollman, S. D. Stranks, A. Petrozza, A. R. S. Kandada, Y. Vaynzof, S. K. Pathak, N. Robertson, and H. J. Snaith, Adv. Energy Mater. 4, 1400166 (2014).

[72] Y. Hu, A. Ivaturi, M. Planells, C. L. Boldrini, A. O. Biroli, and N. Robertson, J. Mater. Chem. A 4, 2509 (2016).

[73] F. Fabregat-Santiago, J. Bisquert, E. Palomares, L. Otero, D. Kuang, S. M. Zakeeruddin, and M. Grätzel, J. Phys. Chem. C 111, 6550 (2007).

[74] (a) F. Kabir, M. M. H. Bhuiyan, M. R. Hossain, H. Bashar, M. S. Rahaman, M. S. Manir, S. M. Ullah, S. S. Uddin, M. Z. I. Mollah, R. A. Khan, S. Huque, and M. A. Khan, Optik 179, 252 (2019); (b) M. Z. Iqbal, S. R. Ali, and S. Khan, Sol. Energy 181, 490 (2019).

[75] M. Li, L. Kou, L. Diao, Q. Zhang, Z. Li, Q. Wu, W. Lu, and D. Pan, J. Phys. Chem. A 119, 3299 (2015).

[76] M. Ye, X. Wen, M. Wang, J. Iocozzia, N. Zhang, C. Lin, and Z. Lin, Mater. Today 18, 155 (2015).

[77] P. Brogdon, H. Cheema, and J. H. Delcamp, ChemSusChem 11, 86 (2018).

[78] N. N. Ghosh, M. Habib, A. Pramanik, P. Sarkar, and S. Pal, New J. Chem. 43, 6480 (2019). 